\title{
A NOÇÃO DE PROJETO NA PSICANÁLISE EXISTENCIAL DE SARTRE
}

\author{
Simeão Donizeti Sass ${ }^{1}$
}

\begin{abstract}
Resumo: O objetivo do estudo é demonstrar que a noção de projeto é importante para o pensamento de Jean-Paul Sartre e indispensável ao método compreensivo que ele denomina psicanálise existencial. Essa noção foi descrita em $O$ Ser e o nada como o movimento da realidade humana de desejar a realização de suas possibilidades fundamentais. Em sua conferência mais famosa, $O$ Existencialismo é um humanismo, vimos a reafirmação da importância dessa noção identificando a relação direta estabelecida com as ações e as escolhas subjetivas de cada pessoa. O método progressivo-regressivo descrito em Questões de método encontra-se no centro da atitude compreensiva. A noção de projeto constitui-se dos momentos: a) de projeto inicial, b) realização concreta de escolhas e ações e c) projeto fundamental quando expressa o sentido e os fins que tomam a liberdade humana.
\end{abstract}

Palavras-chave: Projeto, compreensão, ação.

\begin{abstract}
The aim of the study is to demonstrate that the notion of project is important to the thought of Jean-Paul Sartre and indispensable for understanding method wich he calls existential psychoanalysis. This notion was described in Being and nothingness as the movement of human reality to wish fulfillment of its fundamental possibilities. In his most famous lecture, Existentialism is a Humanism, we reaffirm the importance of this notion by identifying the direct relationship established with the actions and the subjective choices of each person. Progressive-regressive method is described in Search for a Method lies at the center of comprehensive attitude. The notion of project is made up of moments: a) initial project, b) achieving concrete choices and actions and c) when fundamental project expresses the meaning and purpose that take human freedom.
\end{abstract}

Keywords: Project, comprehension, action.

\section{INTRODUÇÃO}

O pensamento de Jean-Paul Sartre ocupou um lugar de destaque na cultura européia entre os anos trinta e cinquenta do século passado. Desde a publicação de $A$ Náusea até o lançamento da Revista Les temps Modernes o chamado existencialismo balizou as discussões no ideário francês. Termos como em-si, para-si, contingência, má-fé, negação, nadificação, totalização passaram a dominar o debate filosófico e cultural em uma época em que as bases da sociedade entravam em um processo de crise e de renovação. Coincidentemente, esse período abarca as duas Grandes Guerras Mundias. Não é sem sentido a afirmação corrente nessa época que Sartre era o pensador que encarnava a crise da so-

1 Doutor em Filosofia e Docente do Departamento de Filosofia da UFMG. 
ciedade burguesa que via seus valores serem questionados pelos horrores de massacres e declínios de antigos impérios coloniais.

Essa perspectiva histórica tem um papel relevante no pensamento de Sartre sob dois aspectos distintos. O primeiro é situacional, o segundo é metodológico. O situacional refere-se ao fato de que Sartre sempre aceitou a tese da historicidade do escritor. Ele demonstrou de forma inequívoca o inevitável caráter concreto de toda escrita defendendo a tese da correlação íntima entre o tempo e a escrita. $\mathrm{O}$ que significa dizer que o escritor tem seu público contemporâneo como alvo primevo de suas ideias e argumentos. É para o leitor contemporâneo que o escrito é endereçado. Escrever é, para Sartre, inserir na temporalidade uma posição. Mesmo que o tema ou a ambientação de uma obra seja o passado ou o futuro, é para o ser humano datado e histórico que a obra é direcionada. Escrever e inscrever-se no presente. No caso de Sartre, essa historicidade também significava abordar os temas e problemas relativos ao mundo vivido por seus leitores. Alguns encontram na obra do existencialista francês uma incoerência temática e a aparente negação de teses em diversos momentos de sua produção. Da náusea ao tema da negação, do engajamento ao método progressivo-regressivo, da literatura engajada ao processo de elaboração da biografia de Flaubert. Essas diferentes facetas do pensamento de Sartre indicam preocupações, aparentemente, distintas. Tal aparência difusa, contudo, revela uma intenção fundamental, como ele mesmo diz em Que é a literatura?, toda escrita tem um tema que engloba os demais, esse tema é a humanidade. Assim, o homem histórico figura como o ponto irradiante da obra de Sartre.

O segundo aspecto, metodológico, reforça o primeiro. Se o tema da escrita de Sartre é a historicidade humana, o método construído ao longo do século vinte, por meio de uma obra extensa e diversificada, que abrangia a literatura, a crítica literária, o ensaio filosófico, o manifesto político, o teatro, todas essas formas de escrita, manifestavam também determinadas escolhas metodológicas. Conceitos como situação, engajamento, temporalidade, contingência serviam para demonstrar a ligação inequívoca entre o homem e a história. Tanto no sentido amplo de cultura e de transformação histórica quanto de uma descrição da vida de uma pessoa concreta e viva, como podemos ver na obra Saint Genet, que analisa e compreende Jean Genet.

Tomando como referência esse traço característico da obra de Sartre, nossa intenção será abordar a noção de projeto existencial. Demonstraremos as vinculações entre alguns dos temas clássicos da obra de Sartre com o irredutível que é o projeto. Tal noção encontra-se dispersa em diversas fases e obras dessa produção, fato que dificulta nossa tarefa. Para contornar essa dificuldade, traçaremos um percurso que vai do surgimento do tema na fase fenomenológica, ou seja $O$ Ser e o Nada, passando pela publicação de $O$ existencialismo é um humanismo até Questões de método, foco central de nossa exposição.

Antes de iniciarmos a exposição desse percurso, devemos considerar alguns aspec- 
tos preliminares. O primeiro deles refere-se ao tema do humanismo. Na clássica conferência dos anos quarenta, Sartre afirma que o seu existencialismo é um humanismo. Tal afirmação poderia confundir os leitores de $A$ Náusea. Naquele que foi o primeiro e mais importante romance de Sartre, publicado no final dos anos trintra, esse tema aparece nos diálogos entre Roquentin e o Autodidata. Curiosamente, é o segundo personagem que defende o humanismo. Roquentin ao contrário, manifesta sua desconfiança e critica o ufanismo que tal ideia envolve. Enquanto o Autodidata exaltava os progressos das ciências, das artes e das tecnologias, representantes do triunfo do homem sobre a terra, Roquentin manifestava seu desconforto relativo ao crescente caminho que o levava ao momento da experiência de uma náusea arrebatadora. Nesse romance, o embate manifesto entre os dois personagens revela que o tema do humanismo provocava a exacerbação de posições antagônicas. Contudo, o tema da existência humana ganhou o centro do existencialismo de Sartre. Como entender tais antagonismos? O debate expresso no romance antecipa o viés de sua abordagem. Se o homem é o tema da escrita de Sartre, isso significa que ele é antes de tudo um problema. Problema que se manifesta na estratégia de perguntar insistentemente pelo sentido de sua existência. Que significado pode ter a palavra homem? Essa é a interrogação que perpassa o seu existencialismo.

Tal problematização ganhou contornos de uma verdadeira renovação da Antropologia. Não é sem razão que em Questões de método Sartre apontou a necessidade de se erigir uma antropologia estrutural e histórica. O debate que surgiu entre Sartre e Levi-Strauss, relativo ao método antropológico, reflete essa escolha temática feita desde o início. Na última grande obra publicada por Sartre nos anos setenta, O Idiota da família, logo no prefácio, surge a pergunta: o que se pode saber de um homem, hoje em dia? Essa obra, como ele mesmo afirma, é a continuação de Questões de método. E a pergunta que pode ser feita, a partir desses dados, é: quais são as questões metodológicas que interessam a Sartre? Tentando responder a essa questão, formulamos o presente estudo situando a noção de projeto como o pólo imantador dessas discussões.

O conceito de Projeto (Entwurf) aparece claramente na obra capital de Karl Jaspers intitulada Psicopatologia Geral. Tal conceito é retomado pela filosofia de Sartre em uma nova concepção, não estritamente ligada ao tema da psicopatologia, mas interpretada em chave existencial. É possível afirmar que ele é o modo de ser do para-si (termo que pode ser compreendido a partir da ideia de realidade humana) manifestando-se na busca de seus fins, dando contornos concretos ao ser da realidade humana. O projeto surge também no contexto de uma nova forma de compreender a realidade humana. Se O Ser e o nada é uma "ontologia fenomenológica", isto é, uma interrogação acerca do modo de ser dos existentes mundanos, os resultados dessa ontologia conduzem a uma resposta ao ser que foi objeto dessa interpelação. Essa resposta passa pela constatação de que a realidade humana é, no seu modo de ser fundamental, "desejo de ser". Se o resultado da ontologia 
fenomenológica revela a realidade humana como desejo de ser, o objeto que surge dessa investigação solicita uma metodologia nova, ela solicita uma psicanálise existencial. Essa psicanálise aparece tematizada na Quarta Parte de $O$ Ser e o nada. Nessa última parte da obra de Sartre vemos surgirem os temas típicos do existencialismo como liberdade, situação, responsabilidade e tantos outros.

A psicanálise existencial será o modo pelo qual Sartre poderá abordar a realidade humana em sua concretude, ou seja, no conjunto de suas escolhas e seus atos. Esse método guardará uma certa inspiração de origem freudiana, pois, como diz Politzer, a psicanálise é a abordagem concreta do drama humano. Ocorre que essa inspiração revelará também desvios e recusas. O principal aspecto a ser questionado será a hipótese do inconsciente. Não abordaremos esse problema aqui, somente apontaremos para as relações estreitas estabelecida por Sartre entre a noção de projeto e o método por ele criado que se chama psicanálise existencial. Ao longo da exposição teremos a oportunidade de demonstrar que essa proposta foi sendo aprimorada em diversas ocasiões, como, por exemplo, a publicação de estudos sobre Baudelaire, Genet e Mallarmé. Estudos que culminam na publicação de $O$ Idiota da família.

\section{A NOÇÃO DE PROJETO EM O SER E O NADA}

A noção de projeto aparece reptidas vezes ao longo das descrições de $O$ Ser e $O$ nada. Como afirmamos anteriormente, o termo Entwurf foi importante também para o pensamento de Karl Jaspers assim como para Heidegger. Essa história pregressa do conceito reaparece na escrita de Sartre sobretudo porque Heidegger é um interlocutor privilegiado. O Dasein, instância capital de Sein und Zeit, foi referência constante para o que Sartre chamava de realidade humana. Se essa herança é inegável, as características próprias da abordagem ontológica de $O$ Ser e o nada transformarão significativamente a noção de projeto.

A tentativa de sintetizar a fenomenologia de Husserl e a filosofia de Heidegger passam pela estratégia de buscar nessa via "fenomenológica" (entre aspas devido ao fato de que Heidegger ultrapassa claramente os objetivos da proposta inicial de Husserl) referenciais teóricos para a elaboração da chamada filosofia do retorno ao concreto, proclamada por Jean Wahl. A via ontológica seguida por Sartre ter por objetivo interpelar a realidade humana. Mas, essa interpelação conduz ao resultado de posicionar essa realidade humana em uma situação histórica e concreta. Isso significa que não é visada a constituição de uma essência da realidade humana. Assim como também era recusada a natureza humana. A reflexão acerca da existência da realidade humana conduz a uma descoberta fundamental: a investigação ontológica, a pergunta pelo ser da realidade humana, pelo modo de ser fundamental dessa existência, conduz ao fato de que essa realidade se revela como desejo 
de ser. Essa constatação, segundo Sartre, opera uma mudança nos rumos da investigação desenvolvida nas páginas de $O$ Ser e o nada.

Se a investigação ontológica acerca da realidade humana revela o desejo de ser, a tarefa dessa investigação passa a ser a revelação dos modos pelos quais esse desejo se manifesta. O que deseja a realidade humana? A resposta a essa pergunta pressupõe, segundo Sartre, uma mudança metodológica. O objeto dessa investigação solicita um método adequado. Esse método será denominado por Sartre de psicanálise existencial. Não temos condições de expor todos os meandros dessa nova fase da investigação. Essa psicanálise guarda algumas semelhanças com a teoria de Freud, mas também revela muitas discordâncias. Em poucas palavras podemos afirmar que esse método visa "elucidar com uma forma rigorosamente objetiva a escolha subjetiva pela qual cada pessoa se faz pessoa, ou seja, faz-se anunciar a si mesmo aquilo que ela é"2.

Somente essa sucinta definição demonstra que a ontologia fenomenológica construída por Sartre diferente significativamente das inspirações fenomenológicas. Da reflexão acerca da relação entre consciência e mundo passa-se para a interpelação relativa ao modo como a realidade humana escolhe seu modo de ser no mundo. É essa preocupação com a dimensão concreta e histórica da escolha que caracteriza o existencialismo de Sartre. A psicanálise existencial terá como traço marcante a busca pelo desvelamento das escolhas, ações e condutas de uma pessoa em seu mundo circundante. É nesse contexto e a partir dessas premissas que surge a noção de projeto.

Como dissemos, o termo projeto aparece inúmeras vezes durante as análises que Sartre empreende ao longo das páginas de $O$ Ser e o nada. Não vamos elencar todas essas passagens. Somente destacaremos os principais aspectos dessa noção. Um momento representativo da aparição da noção de projeto é a possibilidade que todo ser humano tem de viver um projeto de má-fé. Não vamos discorrer sobre a má-fé, somente desejamos demonstrar que a conduta negativa que a consciência pode realizar relativamente a si, ou seja, negar a si recusando a responsabilidade por determinado ato de escolha que envolve a angústia, essa conduta pode ser entendida em um plano mais amplo de um projeto de ser. Os casos clássicos do garçon de café ou da moça recatada exemplificam que as condutas de uma pessoa não são ocorrências esparsas e fragmentadas. O modo constante como essas condutas são repetidas e mantidas durante as sucessivas vivências na história da pessoa revelam que há em cada conduta específica e particular, fática, histórica e contingente, um sentido transcendente e unificador. $\mathrm{O}$ desejo de ser manifesta-se no projeto de má-fé como o sentido escolhido e assumido em sua completude. Um traço característico de personalidade ou a assunção de uma profissão de forma radical demonstram que as escolhas e os atos de um indivíduo seguem a orientação de um projeto de ser.

2 SARTRE, Jean-Paul. O Ser e o nada. Tradução de Paulo Perdigão. Petrópolis: Vozes, 1997, p. 702. 
Esse projeto de ser constitui-se tanto pelas ações cotidianas e irrefletidas quanto pelas decisões refletidas e assumidas voluntariamente. Em outros termos, o projeto de ser existe tanto na forma irrefletida de condutas simples e corriqueiras quanto na dimensão transcendente de ser "totalmente" um garçon de café. As características básicas desse projeto são: as possibilidades que tal pessoa encontra; a dimensão de futuro que a temporalidade de seus atos encerra; a alteridade constitutiva de outro projeto de ser, isto é, de outra manifestação da realidade humana, de outra pessoa e a intenção fundamental desse projeto, os seus fins últimos. O projeto definido por Sartre apresenta também dois aspectos basilares: existe a dimensão inicial do projeto e a dimensão fundamental do projeto. $\mathrm{O}$ projeto inicial é a disposição que a pessoa tem de realizar seu modo de ser fundamental. Esse momento caracteriza-se pelo conjunto de possibilidades e expectativas das ações e condutas. O projeto de iniciar uma carreira profissional, de ser um escritor, por exemplo, configura-se primeiramente pelo esboço de condutas futuras que visam um fim, um horizonte. Sartre apresenta um exemplo clássico desse projeto nas últimas páginas de seu romance mais famoso, A Náusea. Ronquentin, ao final de uma longa experiência angustiante de interrogação acerca do sentido de sua existência decide operar o que Sartre chama de conversão, de mudança radical de vida. Ele decide romper seu relacionamento com sua namorada, abandonar seu trabalho de pesquisa histórica, sair de sua cidade e iniciar a redação de uma obra literária, optando pela vida de escritor. Essa situação revela claramente o que é o início de um novo projeto de vida, de uma mudança radical de direção.

Tal projeto caracteriza-se pela força inegável do futuro. O projeto de fazer coisas novas, de abandonar antigos empreendimentos revela esse desejo de ser, o desejo de ser alguém diferente daquilo que se é. Tal dimensão de conversão e de mudança, contudo, não pode ser pensado sem o seu contraponto, que é a dimensão do projeto fundamental. A psicanálise existencial visa, sobretudo, compreender esse projeto. Ressaltamos a palavra compreender porque uma vida humana não pode ser totalmente explicada da mesma forma que os componentes químicos de uma rocha podem ser fragmentados e analisados. Um traço característico do método que surge com essa psicanálise é a importância fundamental da compreensão. Conceito abordado anteriormente por Dilthey e Heidegger. Compreender um projeto fundamental exige um trabalho meticuloso e complexo de compor, num processo de idas e vindas entre a dimensão pessoal de constituição das escolhas concretas e, de outro lado, o fundo cultural e histórico no qual esse projeto surge. Outro traço importante do projeto fundamental é a característica irredutível de ser a manifestação concreta da liberdade humana. A psicanálise existencial tem por objetivo compreender o modo pelo qual cada pessoa vive a sua liberdade. Em suma, se a ontologia revela a realidade humana como desejo de ser, esse desejo manifesta-se como escolha constante pela liberdade. Não é possível conceber as escolhas concretas que definem o modo de ser, o modo de viver de uma pessoa sem situar essas escolhas no plano mais amplo da 
assunção da liberdade humana com sua condição fundamental. A psicanálise existencial, nas páginas de $O$ Ser e o nada, visa compreender como cada pessoa vive seu projeto fundamental de ser livre, de exercer tal condição escolhendo caminhos e assumindo tais escolhas, em suma, assumindo a responsabilidade pela própria existência.

Nas palavas de Sartre,

\begin{abstract}
As informações que a ontologia pode adquirir sobre as condutas e sobre o desejo devem servir de princípios para a psicanálise existencial. Não significa que existam antes de toda especificação desejos abstratos e comuns a todos os homens, mas sim que os desejos concretos têm estruturas que emergem no estudo da ontologia, pois cada desejo, tanto o de comer ou de dormir como o de criar uma obra de arte, exprime toda a realidade humana ${ }^{3}$.
\end{abstract}

Como podemos notar, o projeto fundamental é a tolidade dos desejos, anseios, escolhas e condutas que uma pessoa adota em sua vida junto aos outros para realizar os seus fins. Essa noção de projeto visa contribuir também para a reflexão acerca da cientificidade e construção da psicologia enquanto ciência. Desde a publicação do estudo sobre as emoções, o Esboço de uma teoria das emoções, Sartre tinha em mente o problema da constituição de fundamentos para a Psicologia que possibilitassem abandonar a visão atomista e associacionista que permeavam muitas teorias psicológicas. A noção de projeto, que também serviu aos propósitos de Jaspers em sua psicopatologia, surge como uma possibilidade de compreensão humana na forma da totalização constante das ações e condutas. Cada pessoa é tomada em sua dinâmica histórica, concreta e totalizadora. Nenhum fato ou escolha pode ser deixado de lado nesse trabalho compreensivo. Desde as escolhas mais banais como o estilo de vestir ou o gosto por determinados alimentos ou esportes, segundo Sartre, revelam a totalidade da pessoa, seu projeto fundamental. Os “comportamentos", portanto, não surgem como resultados de forças externas e motivados por causas inconscientes ou institucionais. Os comportamentos humanos são, nessa perspectiva, escolhidos pelos seus agentes. É essa recusa de determinismos sociais, culturais, biológicos, pulsionais ou econômicos que fazem da psicanálise existencial de Sartre uma verdadeira filosofia da liberdade. É óbvio que cada escolha é feita sob condições, sujeitas a contingências e determinações históricas, mas tais escolhas jamais são justificadas por motivos totalmente alheios ao ser que as faz. É a correlação necessária entre o mundo e a consciência agente que assegura a condição fundamental da liberdade. O homem existe livremente porque ele é cotidianamente impelido a escolher seu modo de ser.

Segundo Sartre,

3 Idem, p. 703. 
O projeto original que se expressa em cada uma de nossas tendências empiricamente observáveis consiste, portanto, no projeto de ser (...) nada há à parte da expressão simbólica que se encontra nos desejos concretos. Não há primeiro um desejo de ser e depois milhares de sentimentos particulares, mas sim que o desejo de ser só existe e se manifesta no e pelo ciúme, pela avareza, pelo amor à arte, pela covardia, pela coragem, as milhares de expressões contingentes e empíricas que fazem com que a realidade humana jamais nos apareça a não ser manifestada por tal homem em particular, por uma pessoa singular ${ }^{4}$.

O projeto, na perspectiva colocada pela psicanálise existencial, visa realizar a máxima existencialista: "a existência precede a essência". A realidade humana, encarnada em cada pessoa singular, faz-se, realiza seu ser pela miríade de escolhas e condutas cotidianas empreendidas concretamente no mundo histórico. Se, segundo Sartre, "ser é fazer-se", o ser desvelado pela ontologia circunscreve sua realidade através das manifestações múltiplas de pessoas que convivem socialmente e que necessitam umas das outras para realizarem seus desejos. É essa síntese de ser e conduta que revela a possibilidade de superação dos determinismos e das teorias atomistas. Essa nova forma de compreender o fenômeno humano pretende totalizar a história da realidade humana em sua universalidade e a vida de uma pessoa concreta em sua singularidade.

Uma característica complementar da noção de projeto é a dimensão moral.

A psicanálise existencial é uma descrição moral, já que nos oferece o sentido ético dos diversos projetos humanos; ela nos indica a necessidade de renunciar à psicologia do interesse, como também a toda interpretação utilitária da conduta humana, revelando-nos a significação ideal de todas as atitudes do homem ${ }^{5}$.

Essa afirmação de Sartre revela que vários níveis de reflexão estão dispostos em sua obra $O$ Ser e o nada. O projeto abrange, simultaneamente, a dimensão moral e psicológica, pois, a ação, a conduta, o comportamento, todas essas perspectivas da atitude prática da realidade humana podem ser consideradas conjuntamente. Sem ser uma reflexão sobre valores prescritivos, a filosofia de Sartre também é uma reflexão acerca do ser do valor. Se a realidade humana é projeto, desejo de ser, transcendência, esse movimento de projeção visa um ser ideal. Retomando a terminologia hegeliana, Sartre afirmar que toda pessoa é desejo de ser a síntese em-si-para-si. O valor é exatamente esse ideal de síntese. Mas o

\footnotetext{
4 Idem, p. 692.

5 Idem, p. 763.
} 
valor se faz na estrita medida em que nunca é realizável empiricamente. Se a realidade humana conseguisse realizar histórica e concretamente o valor ele deixaria de ser para-si para transformar-se na síntese em-si-para-si. Isto é, ele seria o ser que teria conseguido fundar sua existência em si mesmo. Tal possibilidade está vedada ontologicamente ao ser que deseja ser. O para-si existe na forma da negação, falta, transcendência, desejo de ser, em suma, como pro-jeto. Assim, todo ideal, e, por conseguinte, todo valor, é um ideal constantemente almejado, mas jamais alcançado. É a característica do valor que reforça a dimensão de pro-jeto da realidade humana. É nesse sentido que toda existência consciente de si é desejo de ser algo que ainda não existe concretamente. O não ser da possibilidade é o horizonte da existência da realidade humana.

Com essas considerações, a noção de projeto, na obra $O$ Ser e o nada, revela sua importância fundamental para o existencialismo de Sarte. Tal noção também seve para a constituição do método compreensivo que surge com a psicanálise existencial.

Após a publicação de sua ontologia fenomenológica, Sartre inicia um lento e progressivo processo de reformulação metodológica de suas investigações existenciais. $\mathrm{O}$ fim da Segunda Grande Guerra, o fim do nazismo, a perspectiva de uma revolução social protagonizada pela esquerda na França, todos esses novos componentes do mundo cultural francês do pós-guerra incidirão sobre a filosofia de Sartre. O engajamento do escritor será um tema recorrente em seus escritos. Tal viés inovador e transformador materializa-se na publicação da revisa Les Temps Modernes. O fim da guerra trás consigo também o período de maior notoriedade da obra de Sartre. O teatro, os romances, os ensaios literários, todas essas diferentes manifestações colocarão seu pensamento sob os olhares atentos de críticos e entusiastas. Afinal, o que é o existencialismo?

Tal pergunta foi respondida por Sartre em sua conferência O Existencialismo é um humanismo proferida em 1945. Vejamos como a noção de projeto aparece nessa obra.

\section{O PROJETO EM O EXISTENCIALISMO É UM HUMANISMO.}

Essa conferência teve como objetivo principal esclarecer algumas teses fundamentais daquilo que começou a ser chamado nos anos quarenta de existencialismo. Conhecido mais por suas obras teatrais e romanescas do que por sua filosofia, o existencialista angariou rapidamente um público significativo. Isso também despertou o interesse de correntes opostas como marxismo e catolicismo. Para esclarecer certos pontos polêmicos de sua principal obra filosófica $O$ Ser e o nada e para demonstrar as relações entre sua filosofia e sua literatura, a conferência foi usada também como pano de fundo para uma discussão acalorada que ocorreu após o pronunciamento de Sartre. A repercussão dessa conferência ganhou uma importância que superou indubitavelmente as pretensões ini- 
ciais. Com o intuito de divulgar para um seleto grupo de pessoas a conferência, um número limitado de exemplares foi distribuído. O que era inicialmente uma despretensiosa apresentação do existencialismo passou a ser considerado o resumo de todo o pensamento de Sartre. Isso lhe trouxe mais problemas que benefícios. Doravante, a filosofia de Sartre surgia toda a partir de teses como "a existência precede a existência" ou "homem é aquilo que ele faz de si mesmo", ou ainda, "devemos começar pela subjetividade", "o cogito cartesiano". Não temos a intenção de desfazer tais simplificações. Somente tentaremos demonstra como a noção de projeto surge no ambiente da cultura francesa agora dominada pelo existencialismo.

Sartre afirma:

Pois queremos dizer que o homem, antes de mais nada, existe, ou seja, o homem é, antes de mais nada, aquilo que se projeta num futuro, e que tem consciência de estar se projetando no futuro. De início, o homem é um projeto que se vive a si mesmo subjetivamente ao invés de musgo, podridão ou couve-flor, nada existe antes desse projeto; não há nenhuma inteligibilidade no céu, e o homem será apenas o que ele projetar ser ${ }^{6}$.

Como é possível notar, a terminologia usada por Sartre nesse momento é bem diferente daquela empregada em obras de cunho filosófico mais técnico, o homem aparece em primeiro plano e não a realidade humana ou o para-si. O projeto surge como a condição inicial da existência, ressaltando aquilo que aparacia em O Ser e o nada como o projeto inicial, reafirmando a ligação entre as escolhas e o futuro. É importante notar que o termo subjetividade será muito mais frequente a partir dessa conferência, sinal de significativas mudanças terminológicas e metodológicas típicas da aproximação das teses marxistas. O que ressalta igualmente é o centro da reflexão posta na existência. Não surgem mais as referências ao procedimento ontológico da pergunta pelo modo de ser da realidade humana. Tal sentido da existência humana surge sintetizado no homem que vive e escolhe em meio ao mundo da concretude.

Em outro momento Sartre menciona a universalidade do projeto individual:

E, embora os projetos humanos possam ser diferentes, pelo menos nenhum deles permanece inteiramente obscuro para mim, pois todos eles não passam de tentativas para transpor esses limites, ou para afastá-los, ou para negá-los, ou para se adaptar a eles. Conseqüentemente, qualquer projeto, por mais individual que seja, tem um valor universal. Todo projeto, mesmo o do chinês, do indiano ou do negro, pode ser entendido por um europeu. Poder ser compreendido significa que o euro-

6 SARTRE, Jean-Paul. O existencialismo é um humanismo. Tradução de Rita Correia Guedes. São Paulo: Nova Cultural, 1987, p. 6. 
peu de 1945, a partir de uma situação que ele concebe, pode projetar-se para os seus limites. (...) existe uma universalidade de em todo projeto no sentido em que qualquer projeto é intelegível para qualquer homem. Isso não significa de modo algum que esse projeto defina o homem para sempre, mas que ele pode ser reencontrado?

Essas características do projeto revelam a manutenção de algumas teses de $O$ Ser e o nada. O que ele denomina valor universal pode ser interpretado também como a atitude compreensiva que é a tônica da psicanálise existencial, que não tem destaque nessa conferência. O sentido da universalidade liga-se ao fato de poder ser compreendido por outrem, mesmo de uma cultura distinta. Como já ocorria no ensaio de 1943, o projeto deve ser pensado na sua correlação com a situação histórica, concepção teórica que o liga diretamente aos escritos de Jaspers. A dimensão de inteligibilidade de todo projeto humano será desenvolvida posteriormente no sentido de uma verdadeira heurística do atos e condutas praticados pelos homens. O projeto não só é intelegível como disposto expressivamente.

Os exemplos nitidamente corriqueiros apelam para a apreensão das teses existencialistas de forma intuitiva. Se compararmos os estilos das duas obras que analisamos até o momento, a de 1943 e 1945, notaremos uma nítida mudança na estratégia de apresentação das noções fundamentais. Embora Sartre afirme na conferência que o existencialismo é uma filosofia para especialistas e que seus termos técnicos não são de fácil entendimento, a estratégia de discorrer acerca do seu existencialismo para um público não iniciado causou alguns contratempos que jamais foram desfeitos, principalmente por seus opositores. Algumas caricaturas do existencialismo de Sartre foram disseminadas justamente usando passagens e afirmações de O Existencialismo é um humanismo. Se o ensaio de ontologia fenomenológica era de difícil compreesão, o manifesto de 1945 transformou um pensamento meticuloso e complexo em um conjunto de teses facilmente ridicularizadas e criticadas. O debate que se seguiu foi o prenúncio da saraivada de críticas que o existencialismo de Sartre sofreu.

\section{O PROJETO EM QUESTÕES DE MÉTODO}

Mais de dez anos separam a conferência sobre o existencialismo da obra Questões de método. Nesse ínterim alguns estudos de Sartre abordaram o desenvolvimento da psicanálise existencial. Tais estudos basicamente foram elaborados na forma de biografias. Duas delas versaram sobre Baudelaire (1946) e sobre Jean Genet (1952). Sartre dedica o estudo envolvendo a vida e a obra de Baudelaire ao escritor Jean Genet. Seis anos depois, o próprio Genet seria objeto da psicanálise existencial de Sartre. Durante o ano de 1952

7 Idem, p. 16. 
ele produziu outra análise sobre Mallarmé. Tal estudo ficou inédito durante muito tempo. Arlette Elakaim-Sartre publicou em 1986 os extratos dessa pesquisa. Entre 1971 e 1972 foram publicados os estudos acerca de Flaubert.

É possível constatar que a psicanálise existencial teve como foco central a análise das relações entre a vida e a obra desses escritores. Sob certo aspecto tal psicanálise mostra-se como método interpretativo da literatura. Esse aspecto, porém, não deve ser desconectado do pano de fundo metodológico mais amplo da cientificidade da psicologia e da possibilidade de constituição da Antropologia estrutural e histórica anunciada em Questões de método. Na verdade, essas duas facetas da pesquisa de Sartre se complementam. A análise da vida e da obra de escritores serve para demonstrar a viabilidade de constituição da Antropologia projetada por Sartre.

Desde 1943, ou seja, desde o surgimento de O Ser e o nada, o itinerário do pensamento de Sartre foi sinuoso. A tese do engajamento do escritor serviu também para pensar a preocupação com questões sociais e teóricas. A revista Les Temps Modernes, como anuncia seu título, foi usada para debater as questões prementes do século vinte. Tal viés revela a preocupação com a concretude, traço inequívoco do existencialismo. Essa preocupação, ao mesmo tempo, teórica e prática manifestou-se sempre nas obras de Sartre. Uma teoria da abordagem do fenômeno humano não poderia ser a dissociação entre o homem e a história, a separação entre vida e obra. Ao contrário, a práxis, a partir dessa época, passou a ser o paradigma de seu pensamento.

Questões de método foi a primeira manifestação clara da intenção de organizar as bases teóricas do existencialismo, agora, não mais influenciado só pela fenomenologia, mas sintetizado na forma de uma reelaboração das influências de Husserl, Heidegger, Hegel e Marx. Em outros termos, a Antropologia estrutural e histórica inovava muito em relação aos pressupostos de $O$ Ser e o nada. A dimensão social ganhava uma posição privilegiada, os dramas existenciais surgiam ambientados historicamente não só enquanto situação mas resultando de ações coletivas e sob a influência de estruturas sociais.

Essa nova versão da filosofia concreta foi apresentada em Questões de método de forma esquemática e introdutória. $\mathrm{O}$ desenvolvimento de suas teses deu nascimento ao segundo grande estudo elaborado por Sartre, a Crítica da razão dialética. Não temos condições de esmiuçar as teses dessa verdadeira obra prima da filosofia da práxis, somente podemos enunciar as teses do estudo que serviu de prefácio para tal obra, que foi exatamente Questões de método. Essa primeira versão da filosofia da práxis de Sartre surgiu de uma ocasião peculiar. Uma revista polonesa solicitou um artigo sobre a situação do existencialismo de Sartre em meados dos anos cinquenta. Em resposta a esse convite ele escreveu Questões de método. Dessa primeira versão surgiu toda a análise e descrição da dialética como método de compreensão da história. Tal intuito metodológico, contudo, foi amalgamado pelas descrições de acontecimentos da história humana, além de desen- 
volver o início dos estudos sobre Flaubert que foram consagrados na biografia dos anos setenta. Como é possível notar, esses estudos dos anos cinquenta foram importantíssimos para o pensamento de Sartre. Constituindo-se a base de suas produções ulteriores.

Após essa breve apresentação dos aspectos históricos e teóricos de Questões de método, a análise da noção de projeto será o próximo passo.

Essa obra está dividida em três partes, além da conclusão, a primeira tem como título "Marxismo e Existencialismo", a segunda "O problema das mediações e das disciplinas auxiliares" e a terceira "O método progressivo-regressivo". A primeira atende especificamente aos interesses da revista de situar o existencialismo frente aos problemas fundamentais de sua época e, nesse aspecto, o marxismo foi posto como a filosofia dominante no senário teórico e cultural. Ali Sartre situa-se como um companheiro de viagem do marxismo mas declara que o seu existencialismo conserva um papel fundamental: desvelar a importância do ser humano na filosofia marxista. A segunda parte avança no sentido de revelar a necessidade de uma verdadeira síntese das chamadas ciências humanas, da história, da psicologia e da sociologia. Tais áreas do saber deveriam considerar a possibilidade de trabalharem em conjunto dado que seu objeto seria o mesmo, ou seja, o ser humano estaria na base de todas as ciências humanas. A terceira parte apresenta uma digressão importante acerca da psicanálise existencial, ela é a apresentação do método que constituiria a demonstração da relação necessária entre a vida e a obra de um fenômeno histórico. É interessante destacar que Flaubert sempre surge como exemplo em diversos momentos de Questões de método. Antecipando as descrições da Crítica e do Idiota da família.

Vamos privilegiar a análise da terceira parte, do método progressivo-regressivo. Nela encontramos significativas contribuições para nosso estudo.

Um dos temas centrais dessa parte e de toda a obra de Sartre é a questão da práxis, ou seja, da ação histórica e consciente. Ainda que, desde a fase da fenomenologia dos anos trinta e quarenta, a ação tenha resguardado sempre um lugar de destaque no existencialismo de Sartre, o sentido que o marxismo atribuiu a esse termo foi de fundamental importância. Não é sem razão que a referida parte inicia-se com a consagrada citação da obra marxiana: "Os homens fazem, eles próprios, sua história, mas num meio dado que os condiciona" " É esse duplo aspecto da ação, a de ser feita pelo homem e de ocorrer em um meio condicionante, ou seja, uma relação de dupla determinação entre a liberdade e o condicionamento, que dispõe os termos do problema. Tal situação surgia nas descrições das ações da realidade humana em bases fenomenológicas, nas publicações dos anos quarenta, mas, agora, o papel do condicionamento, do peso das estruturas ganha maior destaque, talvez, não tanto pela mudança da realidade concreta, mas pelo enfoque que o

8 SARTRE, Jean-Paul. Questão de método. Tradução de Bento Prado Jr. São Paulo: Nova Cultural, 1987, p. 149. 
pensamento francês passou a dar ao que era denominado estrutura. É também contra e com o estruturalismo francês dos anos cinquenta e sessenta que Sartre dialoga.

Para o existencialista, a realidade na qual o ser humano vive é a liberdade, essa é sua condição insuperável, ou seja, inegável. Esse pressuposto interfere no modo como a ação é realizada. Um princípio que se mantém constante na obra de Sartre é o fato de que toda ação humana pressupõe a consciência. $\mathrm{O}$ que não significa que toda ação seja conhecida integralmente pelo ator. A distinção entre consciência e conhecimento, estabelecida desde as primeiras obras, remonta aos princípios da fenomenologia, que ensina que existem os atos irrefletidos e reflexivos. A ação poder ser identificada nos dois momentos mas o conhecimento somente ocorre no segundo. Daí a questão de situar o homem na ação, no mundo concreto, na práxis. Nem todo ato consciente é conhecido pelo autor mas todo ato realizado manifesta a consciência daquele que o pratica, dado que todo ato tem, necessariamente, uma intenção. É esse sentido de intencionalidade que Sartre retém da fenomenologia. É por isso que o princípio freudiano do inconsciente não será aceito sem discussão. A situação era o conceito que desde Jaspers atribuía historicidade aos atos humanos. Sartre reafirma que toda ação humana somente ocorre em uma situação histórica datada. Assim, é possível identificar certos traços de similitude entre o marxismo e a fenomenologia quando ambos afirmam que toda ação humana concreta ocorre no mundo histórico. A grande questão está em avaliar o peso que essa realidade histórica reserva para a ação humana livre. E o problema que surge é: o homem é ou não condicionado pelo meio que o circunda, qual é o grau de comprometimento desse condicionamento. Em suma, o condicionamento questiona se o homem age livremente ou não. Portanto, constatar o total condicionamento das ações humanas ou aceitar que há um jogo de dupla determinação, um vai e vem, um jogo constante entre determinação e liberdade, uma verdadeira dialética sem síntese entre a historicidade e a liberdade humana é crucial para as pretensões de qualquer abordagem sobre o homem.

A síntese operada entre a dimensão da práxis, da ação de um homem em sua historicidade e as condições objetivas nas quais ele vive surge de forma clara na seguinte afirmação:

Assim, a alienação pode modificar os resultados da ação, mas não sua realidade profunda. Recusamos confundir o homem alienado com uma coisa, e a alienação com as leis físicas que regem os condicionamentos de exterioridade. Afirmamos a especificidade do ato humano, que atravessa o meio social, conservando-lhe as determinações, e que transforma o mundo sobre a base de condições dadas. Para nós, o homem caracteriza-se antes de tudo pela superação de uma situação, pelo que ele chega a fazer daquilo que se fez dele, mesmo que ele não se reconheça jamais em sua objetivação. Esta superação, encontramo-la na raiz do humano?.

9 Idem, p. 151-152. 
A alienação é um conceito clássico da filosofia hegeliana, complexo demais para explicarmos nesse momento da argumentação, somente destacamos o fato de que tal conceito é pensado, por Sartre, a partir da noção de projeto. Em poucas palavras, a alienação é vivida como projeto, experienciado individualmente e, ao mesmo tempo, como estrutura social. Mesmo que a ação seja alienada, ela ainda pertence ao seu autor e pode ser objeto de responsabilização. Não confundir alienação e reificação significa conservar o ser humano enquanto tal e não como simples produto de condições materiais. Mesmo que as condições materiais e sociais sejam adversas e neguem ao homem a sua condição, é negando essa negação, isto é, agindo contra essa determinação absoluta, contra essa desumanização que cada pessoa pode afirmar-se recusando a alienação sistêmica. Assim, a decisão de lutar contra o processo alienante ou aderir a esse processo pressupõe a liberdade humana. $\mathrm{O}$ fazer a história e o ser feito por ela são resultados das ações humanas no mundo. A alienação é a manutenção da situação determinista, a negação dessa situação é a superação. Nesse momento Sartre enuncia a frase repetida anos antes na biografia de Genet: o homem caracteriza-se antes de tudo pela superação de uma situação, pelo que ele chega a fazer daquilo que se fez dele. Nessa frase encontra-se a compreensão dialética da existência humana. É por isso que ele considera que a dialética é o único método apropriado para a Antropologia, para a História, para a Psicologia, enfim, para as ciências humanas. Porque esse método consegue sintetizar os dois lados do processo, o homem concreto e a história concreta. A superação de cada situação, seja ela adversa ou não, é a condição primeva da existência. Desse modo, superação e projeto assemelham-se no sentido de conferir ao ser humano a condição de constante negação e constituição de seu ser. Se a ação é o ser do homem, se sua práxis é a sua realidade, essa condição agente transforma sua vida em um constante processo de auto-constituição.

O projeto, nesse contexto, é uma dupla relação simultânea:

Em relação ao dado, a práxis é negatividade: mas trata-se sempre da negação de uma negação; em relação ao objeto visado, ela é positividade: mas esta positividade desemboca sobre o 'não-existente', sobre o que ele ainda não foi. Simultaneamente fuga e salto para frente, recusa e realização, o projeto retém e revela a realidade superada, recusada pelo movimento mesmo que a supera: assim, o conhecimento é um momento da práxis, mesmo da mais rudimentar; mas esse conhecimento nada tem de um Saber absoluto ${ }^{10}$.

É notória a aproximação que Sartre realiza nesse momento entre as reflexões acerca

10 Idem, p. 152. 
de sua compreensão do marxismo e a psicanálise existencial iniciada em $O$ Ser e o nada. $\mathrm{Na}$ verdade, o marxismo é usado para enriquecer suas reflexões acerca da realidade humana que agora é pensada a partir da práxis individual/coletiva. Se o homem vive agindo e construindo sua existência, tal ação particular e concreta integra a construção da própria história humana em sua totalidade. O projeto surge nessa construção teórica como o momento singular da existência coletiva. A superação de uma situação não existe sem assunção dessa mesma situação. É por isso que toda transformação efetiva, seja de uma vida ou de uma sociedade, pressupõe a consciência do momento e o projeto de superação dessa realidade. Assunção e negação da situação são momentos complementares desse processo ininterrupto de construção histórica da existência. É por essa razão que a descrição compreensiva da vida de Flaubert é também a compreensão do romance contemporâneo, da França, da realidade humana. Universalidade e singularidade sintetizam-se na vida de cada pessoa.

O projeto explicitado por Sartre é parte integrante da compreensão concreta da realidade humana que se faz como práxis. É um construto teórico que tenta abarcar a concretude da existência humana em suas nuances mais específicas. Segundo Sartre,

\begin{abstract}
Apenas o projeto, como mediação entre dois momentos da objetividade, pode dar conta da história, isto é, da criatividade humana. É preciso escolher. Com efeito, ou se reduz tudo à identidade (o que leva a substituir o materialismo dialético pelo materialismo mecanicista), ou então faz-se da dialética uma lei celeste que se impõe ao universo, uma força metafísica que engendra por si mesma o processo histórico (...), ou ainda devolve-se ao homem singular seu poder de superação pelo trabalho e pela ação (...) Somente os caracteres do projeto humano permitem compreender que este resultado seja uma realidade nova e provida de uma significação própria, em lugar de ser muito simplesmente uma média ${ }^{11}$.
\end{abstract}

A noção de projeto revela-se também como noção chave da crítica de Sartre aos marxistas ortodoxos que compreendiam as ações humanas como simples resultados das condicionantes sociais e fadadas a serem repetições de condutas alienadas enquanto a revolução social não destruísse os fatores de alienação. Esse reducionismo travestido de teoria social, principalmente do Partido Comunista Francês, que tantos ataques desferiu contra Sartre, desde os tempos da invasão nazista, foi objeto da crítica de Sartre. O resultado foi a publicação de Crítica da razão dialética.

Embora Sartre tenha tomado a dialética como método, ele opera sua crítica porque ela foi transformada pelo partido em ferramenta de determinação mecanicista das 
ações humanas. A práxis transformou-se em ação reflexo. Para superar tal desvio da orientação marxista, Sartre resgata a criatividade da práxis humana. A história não é somente a instância das determinações materiais e alienantes do processo exploratório do capitalismo, ela é também o lugar da transformação dessa condição. Nem materialismo dialético mecanicista, nem metafísica abstrata da história. É preciso, segundo Sartre, devolver, ou melhor, reabilitar a capacidade humana de agir transformando e não apenas de reproduzir condições dadas. Agir também é escolher a possibilidade da mudança, da superação. Se há o projeto de manutenção da alienação, também há a possibilidade de construção de projetos libertadores, como Sartre defende e denuncia nas relações entre as metrópoles e as suas colônias, sendo a Argélia o caso mais emblemático. O projeto surge, então, como uma noção que abarca tanto as especificidades de escolhas e práticas de um indivíduo quanto a possibilidade de transformações sociais pela cooperação desses projetos concretos.

A última questão que gostaríamos de destacar em nosso estudo é a questão da linguagem. Esse tema sempre ocupou lugar de destaque na obra de Sartre. Não temos condições de explorar todas as variantes que o tema desperta, somente assinalamos a pertinência da discussão no momento histórico em que o estruturalismo trará contribuições fundamentais para uma revolução nos paradigmas da linguagem. É também com o estruturalismo que Sartre dialoga, sobretudo com a antropologia de Levi-Strauss. Para mencionar somente uma dimensão do problema, Sartre relaciona a questão da linguagem ao tema do projeto. Sartre afirma:

Mas a relação do signo ao significado não pode ser concebida aqui na forma de uma significação empírica: o movimento significante - na medida em que a linguagem é, ao mesmo tempo, uma atitude imediata de cada um em relação a todos e um produto humano - é ele próprio projeto. Isto significa que o projeto existencial estará na palavra que o denotará, não como o significado - que, por princípio, está fora -, mas como o seu fundamento original e sua estrutura mesma. E, sem dúvida, a própria palavra linguagem tem uma significação conceitual: uma parte da linguagem pode designar o todo conceitualmente. Mas a linguagem não está na palavra como realidade que funda toda nominação; é antes o contrário, e toda palavra é toda a linguagem. A palavra 'projeto' designa originalmente certa atitude humana ('fazem-se projetos') que supõe como seu fundamento o pro-jeto, estrutura existencial; e esta palavra, enquanto palavra, não é ela própria possível senão como efetuação particular da realidade humana enquanto ela é pro-jeto. Neste sentido, ela não manifesta por si mesma o projeto de que emana, senão à maneira pela qual a mercadoria retém em si e nos reenvia o trabalho humano que a produziu ${ }^{12}$.

12 Idem, p. 187. 
A linguagem é abordada por Sartre no bojo de sua filosofia da práxis. A linguagem é parte integrante do mundo cultural que permeia a vida humana. Uma vez mais, a imagem do vai e vem, do jogo, da relação dialética de dupla determinação é usada para pensar o problema. O homem é feito pela linguagem tanto quanto a produz. A linguagem é mediada pelas ações humanas e tais ações são mediadas pela linguagem. Se a linguagem possui uma estrutura que a torna um ser, tal estrutura somente pode ser pensada, usada e definida, segundo Sartre, nas relações concretas da vida no mundo, no âmbito do mundo da vida. Se a linguagem surge e compõe o mundo concreto, ela é fruto das ações humanas. Se é assim, tais ações surgem em um contexto de projeto fundamental. Daí a necessidade de situar a práxis linguagem no plano do projeto. Vemos por essa razão a importância da noção de projeto para a psicanálise existencial: toda forma de uso da linguagem somente pode ser compreendida se ela estiver situada no plano do projeto fundamental de seu produtor. Assim como a mercadoria, a linguagem é produzida pelo o homem e o produz de alguma maneira. Flaubert, nesse contexto, é influenciado por suas obras e também o autor daquilo que o faz. A máxima: "fazer algo com aquilo que fazem de nós" serve também para a definição da estrutura da linguagem. Em suma, o homem não recebe passivamente a estrutura da linguagem, ele a faz e a transforma, assim como a reproduz. O trabalho de compreensão da obra de Flaubert solicita a compreensão do projeto que o autor almeja. Elucidar o sentido de uma frase ou de uma obra é também elucidar o projeto existencial que a torna possível.

Assim,

Na linguagem, em outras palavras, o homem se designa enquanto é objeto do homem. Mas, no esforço por encontrar a fonte de todo signo e, por conseguinte, de toda objetividade, a linguagem volta-se sobre si mesma para indicar os momentos de uma compreensão perpetuamente em ato, já que nada mais é do que a existência. Dando nomes a esses momentos, não os transformamos em Saber - já que este concerne ao inerte e ao que chamaremos mais adiante de prático-inerte -, mas balizamos a atualização compreensiva com indicações que reenviam simultaneamente à prática reflexiva e ao conteúdo da reflexão compreensiva. Carência, negatividade, superação, projeto, transcendência, formam, com efeito, uma totalidade sintética em que cada um dos momentos designados contém todos os demais ${ }^{13}$.

É possível, a partir dos dados apresentados, demonstrar a importância da noção de projeto para a obra de Sartre e, especificamente, para o plano da psicanálise exis- 
tencial. Os termos mencionados acima, carência, negatividade, superação, projeto, transcendência, perfazem os temas das obras publicadas pelo existencialista desde os anos trinta. E o projeto surge como síntese dos atos de uma pessoa que apontam para a sua sociabilidade intrínseca e para a escolha fundamental da existência livre. A noção de projeto torna possível a compreensão de uma pessoa a partir das intenções manifestas por seus atos. O uso da linguagem, a produção de um romance, de um conto, enfim, da práxis da escrita, somente ganha seu sentido mais completo quando surge como manifestação de uma existência concreta e histórica, como fruto de um projeto pessoal. A tarefa compreensiva da linguagem necessita assumir tal procedimento, pois a desconsideração dessa perspectiva pode transformar a linguagem e seu ator em um puro em-si.

\section{CONCLUSÃO}

Ao final de nosso estudo, podemos afirmar que a noção de projeto é importante para o pensamento de Jean-Paul Sartre e indispensável para o método compreensivo que ele denomina psicanálise existencial. Essa noção foi descrita em $O$ Ser e o nada como o movimento da realidade humana de desejar a realização de suas possibilidades fundamentais, o desejo de ser manifestou-se como o projeto fundamental que se concretiza pelo conjunto de ações e condutas que uma pessoa opera visando sua completude. A atitude compreensiva da psicanálise existencial mostrou-se fundamental para a elucidação desse projeto. Em sua conferência mais famosa, O Existencialismo é um humanismo, vimos a reafirmação da importância dessa noção identificando a relação direta estabelecida com as ações e as escolhas subjetivas de cada pessoa. Em Questões de método identificamos o método progressivo-regressivo sendo descrito e colocando no centro da atitude compreensiva o projeto. Noção que constitui-se de projeto inicial, realização concreta de escolhas e ações e que define-se como projeto fundamental quando expressa o sentido e os fins que tomam a liberdade humana. Finalmente, identificamos que a linguagem é um dos momentos do projeto, dado que todas as ações realizadas por qualquer ser humano no mundo sintetizam a totalização de seus aspectos e o sentido fundamental de concretizar o projeto de ser pessoa em sua totalidade. Assim, a descrição da obra de Flaubert somente pode ser empreendida se o projeto fundamental de escritor surge em meio aos dramas e escolhas do maior romancista que a França conheceu no século dezenove. 


\section{REFERÊNCIAS BIBLIOGRÁFICAS}

BERGSON, Henri. Ensaio sobre os dados imediatos da consciência. Tradução de João da Silva Gama. Lisboa: Edições 70, 1988.

. A Evolução Criadora. Tradução de Bento Prado Neto. São Paulo: Martins Fontes, 2005.

BORNHEIM, Gerd A. Sartre. São Paulo: Editora Perspectiva, 1984.

HEGEL, G. W. F. Morceaux choisis. Traduzido por Henri Lefebvre e Norbert Guterman. Paris: Gallimard, 1939.

. Fenomenologia do Espírito. Parte I. Tradução de Paulo Meneses. Petrópolis: Vozes, 1992.

Fenomenologia do Espirito. Parte II. . Tradução de Paulo Meneses. Petrópolis : Vozes, 1993.

HEIDEGGER, Martin. L'Être et le temps. Tradução de Rudolf Boehm e Alphonse de Waelhens. Paris: Gallimard, 1964.

. Que é Metafisica? Tradução de Ernildo Stein. São Paulo: Duas Cidades, 1969. . Lettre sur l'humanisme. Tradução de Roger Munier. Paris: Aubier, 1983.

HOWELLS, Christina. The Cambridge Companion to Sartre. Cambridge: Cambridge University Press, 1992.

HUSSERL, Edmund. Recherches Logiques. Traduzido por Hubert Elie, Arion L. KelKel e René Schérer. Paris : P. U. F., 1961. . Idées directrices pour une phénoménologie. Tradução de Paul Ricoeur. Paris: Gallimard, 1989. . Méditations Cartésiennes. Versão francesa de Gabrielle Peiffer e Emmanuel Levinas. Paris: Vrin, 1966.

KIERKEGAARD, S. A. O conceito de ironia. Tradução de Álvaro L. M. Valls. Petrópolis: Vozes, 1991. . O Conceito de Angústia. Tradução de Torrieri Guimarães. São Paulo: Hemus, 1968.

MÜLLER, Marcos L. "A má-fé e a teoria de negação em Sartre" in Manuscrito, vol. V, no 2, Campinas, abril/1982.

NATANSON, Maurice. A Critique of Jean-Paul Sartre's Ontology. Nebraska: University of Nebraska, 1951.

PHILONENKO, Alexis. "Liberté et mauvaise foi chez Sartre" in Revue de Métaphysique et de Morale, $\mathrm{n}^{\circ}$ 2, 1981.

PRADO Jr., Bento. Presença e campo transcendental. São Paulo: Edusp, 1988.

PRESSEAULT, Jacques. L'Etre-pour-autrui dans la philosophie de Jean-Paul Sartre. Bruxelas: 
Desclée de Brouwer, 1970.

ROUGER, François. Le Monde et le Moi. Paris: Méridiens Klincksieck, 1986.

SEEL, Gerhard. La dialectique de Sartre. Tradução de E. Müller, Ph. Muller e M. Reinhart. Lausanne : Ed. L'Age d'Homme, 1995.

SARTRE, Jean-Paul. Critique de la raison dialectique. Paris: Gallimard, 1960. . L'Être et le Néant. Paris: Gallimard, 1943. Esquisse d'une théorie des émotions. Paris : Hermann, 1965. . L'Existentialisme est un humanisme. Paris: Nagel, 1946. . O existencialismo é um humanismo. Tradução de Rita Correia Guedes. São Paulo: Nova Cultural, 1987. . L'Idiot de la famille, Gustave Flaubert de 1821 até 1857. Paris, Gallimard, 1971. . L’Imaginaire. Paris: Gallimard, 1940. . L'Imagination. Paris: Presses Universitaires, 1936. La Nausée. Paris, Gallimard, 1938. . Questão de método. Tradução de Bento Prado Jr. São Paulo: Nova Cultural, 1987. . O Ser e o nada. Tradução de Paulo Perdigão. Petrópolis: Vozes, 1997. . Situations I. Paris, Gallimard, 1947. . La Transcendance de l'ego. Paris : Vrin, 1978.

SILVA, Franklin Leopoldo e. "A Transcendência do ego. Subjetividade e narrabilidade em Sartre" in Sintese. Revista de filosofia, v. 27, n. 88, 2000.

WAHL, Jean. Le malheur de la conscience dans la philosophie de Hegel. Paris: Presses Universitaires de France, 1951. . Études kierkegaardiennes. Paris : Vrin, 1949. 